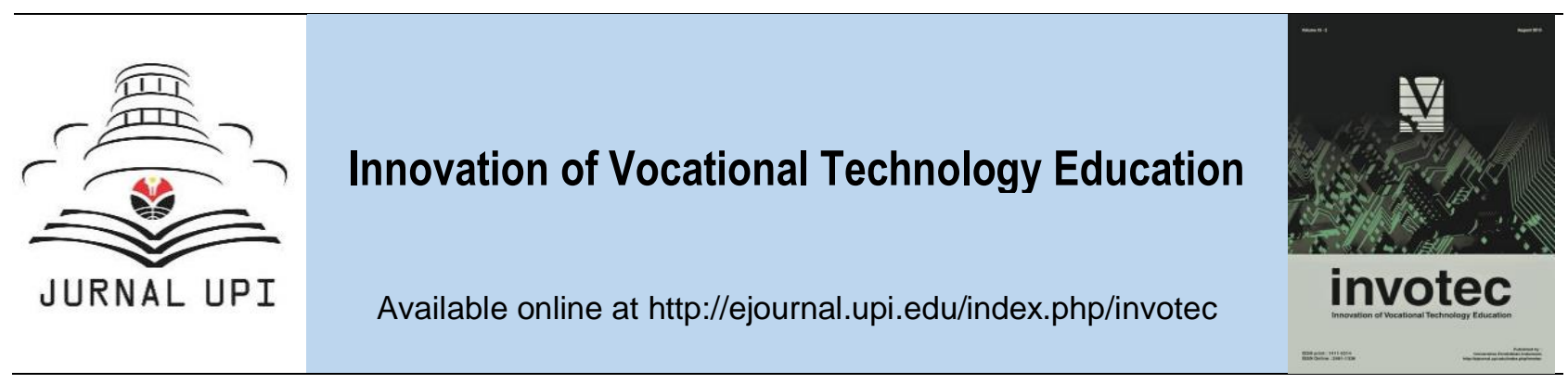

\title{
The Implementation of Problem-Based Learning Model in Maze Game of Multimedia Learning for Vocational School Students
}

\author{
D. Rohendi and H. Sutarno \\ Universitas Pendidikan Indonesia, Indonesia
}

\section{ARTICLE INFO}

Article history:

Received 6 May 2018

Received in revised form 13 June 2018

Accepted 20 July 2018

Available online 31 August 2018

Keywords:

problem based learning

maze game

multimedia learning

Corresponding author:

dedir@upi.edu

\begin{abstract}
Research on the use of games in learning has been growing rapidly. However, the material delivery is still conventional, without considering any certain learning methods. Yet, the method in learning is a factor that determines the success of teaching. Therefore, the purpose of this research is to find out how the implementation of Problem Based Learning model in the development of maze game of multimedia learning used. Maze game of multimedia learning devel-oped was implemented to the students of vocational school students. The results showed that the implementation of Problem-Based Learning in maze game of multimedia learning is worthed and categorized as excellent accord-ing to not only validation of expert of subject matter and media, but also students' response.
\end{abstract}

\section{Introduction}

Learning has changed into multidirectional learning. Conventional learning has also Teachercentered learning has now changed into student-centered learning. A one way changed into multimedia learning. Advances in technology and the development of new and powerful educational tools brought technology integration into instructional practices (Bakir, 2016). Thus, multimedia in learning is now a necessity that cannot be avoided. Therefore, designing multimedia should be conducted by using various interesting shapes, in which one of them is in the form of game.

Game development during the past two decades has been increasing rapidly. The first computer game that was ever created was probably OXO by Alexander Douglas in 1952 (Kent, 2001). It was a version of tic-tac-toe games that was developed for entertainment purpose. Since then, the purpose of game developments continues to grow. It was affected by the development of the reasons why people play games. There are some common reasons why people play game, such as fantasy/exploration, proving oneself, social lubrication, exercise, needs for acknowledgement, and also educational reasons (Crawford, 2000)

Multimedia games allow students to be more active in learning, since they are encouraged to be independent and as if engaged in his/her own situation experienced (Anneta, 2008). The game adopted in this multimedia learning are in the shape of maze, namely a game to find purpose through a complicated and tortuous way. The material delivery of multimedia determines the success of multimedia use and learning outcomes. However, the delivery of content/material in multimedia is still conventional, without considering any appropriate learning method. In fact, the method of 
learning is one factor that determines the success of teaching. The learning method in multimedia also determines whether the material can be delivered well and understood by students or not.

One of the innovative learning models that can be implemented in improving learning outcomes is Problem Based Learning (PBL). PBL model is a model of learning associated with contextual learning (Siburian, 2010). PBL model begins by giving a problem to be solved. By using PBL, the student will be easier to absorb the material, because they are directly active in the problem solving process. Students who are able to solve the problem would be easier to draw their own conclusions. Thus, this model is suitable to be implemented in multimedia.

Education has many goals. We can breakdown educational goals as follows: 1) acquisition and retention of basic, important, knowledge, and skills; 2) understanding of one's acquired knowledge and skills; 3 ) active use of one's acquired knowledge and skills; 4) learning to learn and to help other learn; 5) learning to work both individually and collaboratively; 6) learning for transfer of learning; 7) learning to improve one's creativity; 8) learning that helps increase one's level of cognitive development and cognitive maturity; 9) learning to make effective use of new aids to solving problems and accomplishing tasks; 10) learning to make use of all of the above in doing things, developing products (Perkins, 1992; Moursund, 2006).

Furthermore, there is a discipline that concerns in games for educational purpose called Games-in Education. It received increased legitimacy in October 2003 when the Massachusetts Institute of Technology announced an initiative to study educational roles of computer games (Games-to-Teach Project).

It is important to distinguish between educational games and edutainment games prior to proceeding with a review focused on educational game design. Educational games require strategizing, hypothesis testing, or problem-solving, usually with higher order of thinking rather than rote memorization or simple comprehension. In contrast, edutainment games are those which follow a skill and drill format in which player either practice repetitive skills or rehearse memorized fact (Dondlinger, 2007).

Along with its development, the genre of the computer games that are created becomes varied. There are some common game genres such as combat, maze, sports, war, educational, interpersonal games, etc. (Crawford, 2000). The game genre that will be used in this research is a maze game. It contains the maze of paths through which the players must move. Sometimes one or more enemies pursue the player through the maze. A simple example of this game is Pac-Man games.

In maze games genre, the main things that should be managed is the maze generator. There are several ways of generating the maze, which are manually generated by humans and using procedural algorithms. Generating maze manually is very inefficient, and the maze result would be less varied, so then the game would be more predictable and boring. The usage of procedural algorithms had many advantages, such as providing the player with unique experience every time they play the game (Headland, et. al., 2014). Having an inexhaustible source of new maps means that levels become less predictable. For some players, the core mechanic of the game design requires the real time generation, maps can be adjusted to match player needs and abilities, and it can be used as an assisting authoring tool for complementing human creativity and level design expertise existent within commercial game development (Lawrence, Yannakakis and Togelius, 2014).

The learning process conducted in school focuses a lot on teacher. Teachers themselves still teach student by using conventional methods. This is in line with the statement of Davies (2000), that "one that is often overlooked is the tendency to forget that the nature of learning is students' learning instead of teaching".

Teachers are required to choose a suitable model/method to be used in the learning process in the classroom. The model chosen should be able to improve passion and accelerate students to be more active in the class. One model that can accelerate student is Problem Based Learning (PBL). PBL helps students to improve thinking skills. PBL was developed by Barrows (1996). Now, this model has been expanded to various educational institutions (Amir, 2010). PBL is the most significant innovation in education (Boud and Feletti, 1997) because through PBL students' thinking skills has really been optimalized through a systematic work process in group or team, so that students be able to empower, honing, testing, and develop the capacity to think in continuity (Tan, 2003). As for the characteristics of PBL are: 1) Problem is the beginning of a learning process; 2) The problems arose in real life and unstructured; 3 ) The problem requires multiple perspectives; 4) 
The existing problem demands a way of thinking and knowledge of students to be identified; 5) The learning is collaborative, communicative and cooperative; 6) Students are required to be independent by utilizing various sources of knowledge (Tan, 2003).

It can be concluded that PBL has different characteristics from other learning models. In PBL, a problem given to a student should be able to generate one's understanding of a problem. Students are required to think critically and solve the problems. Application of PBL in teaching also requires teacher's readiness in the learning process. Students should also be prepared to be actively involved in learning. The problems discussed should be relevant and appropriate to the demands of life both in the present and future (Johnson and Johnson, 2008).

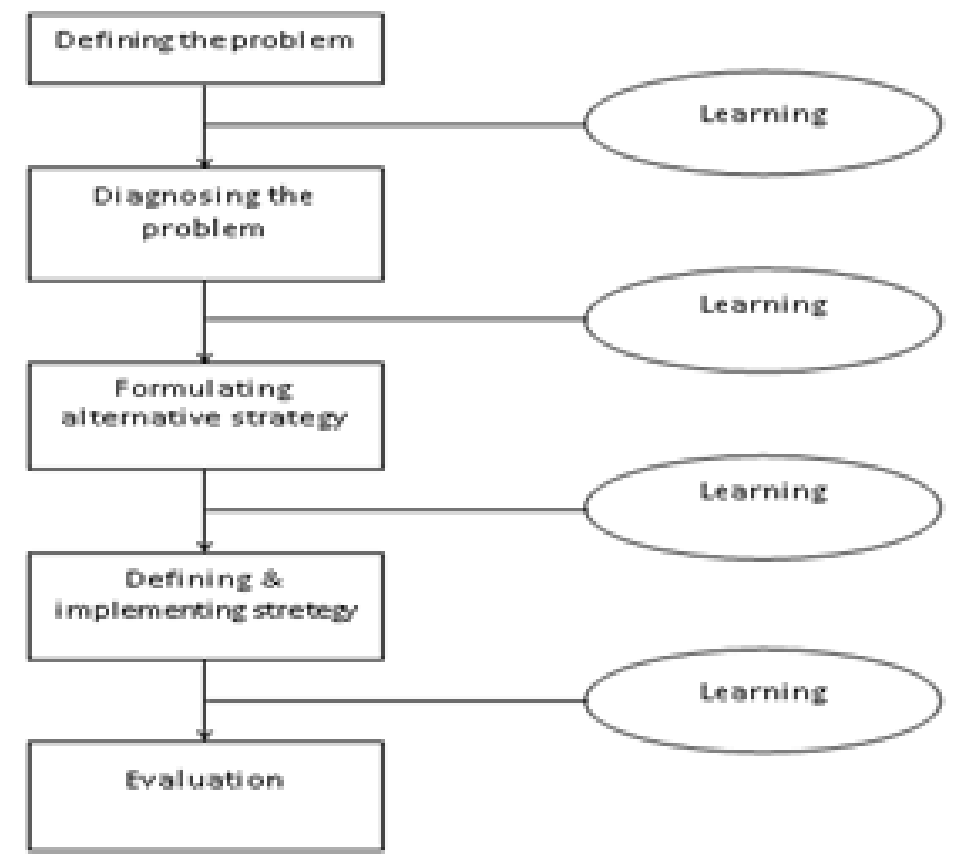

Figure 1. The Flowchart of PBL model

The process of flowchart in Figure 1 can be described as follows: a) Defining the problem (i.e. formulating the problem of certain events which contain issues of the conflict, so it is clear what will be reviewed). b) diagnosing the problem (i.e. the stage to determine the cause of the problem, analyze various factors in problem solving and can be conducted with discussion). c) formulating alternative strategy (i.e. the stage where the students test each action formulated. Students are encouraged to give opinion argumentation about every possibility of an action being taken). d) defining and implementing the strategy of choice (i.e. the decision about which strategies can be taken). e) evaluation (i.e. stages of evaluation of overall activities and results as the strategy applied).

\section{Method}

Developing multimedia maze games adopts a comprehensive lifecycle methode (Munir, 2013), such as in Figure 2, which includes several phases as follows: 1) Analysis: specifying multimedia development needs by conducting a preliminary study, analysis of user, software and hardware. 2) Design: making a flowchart, storyboard, and material design which are adjusted to the curriculum and PBL model. 3) Development: making multimedia in accordance with the design; conducting black-box testing and assessment by experts of materials and media. 4) Implementation: implementing multimedia toward a number of samples. 5) Assessment: assessing the strengths, the shortcomings of the implementation phase. 


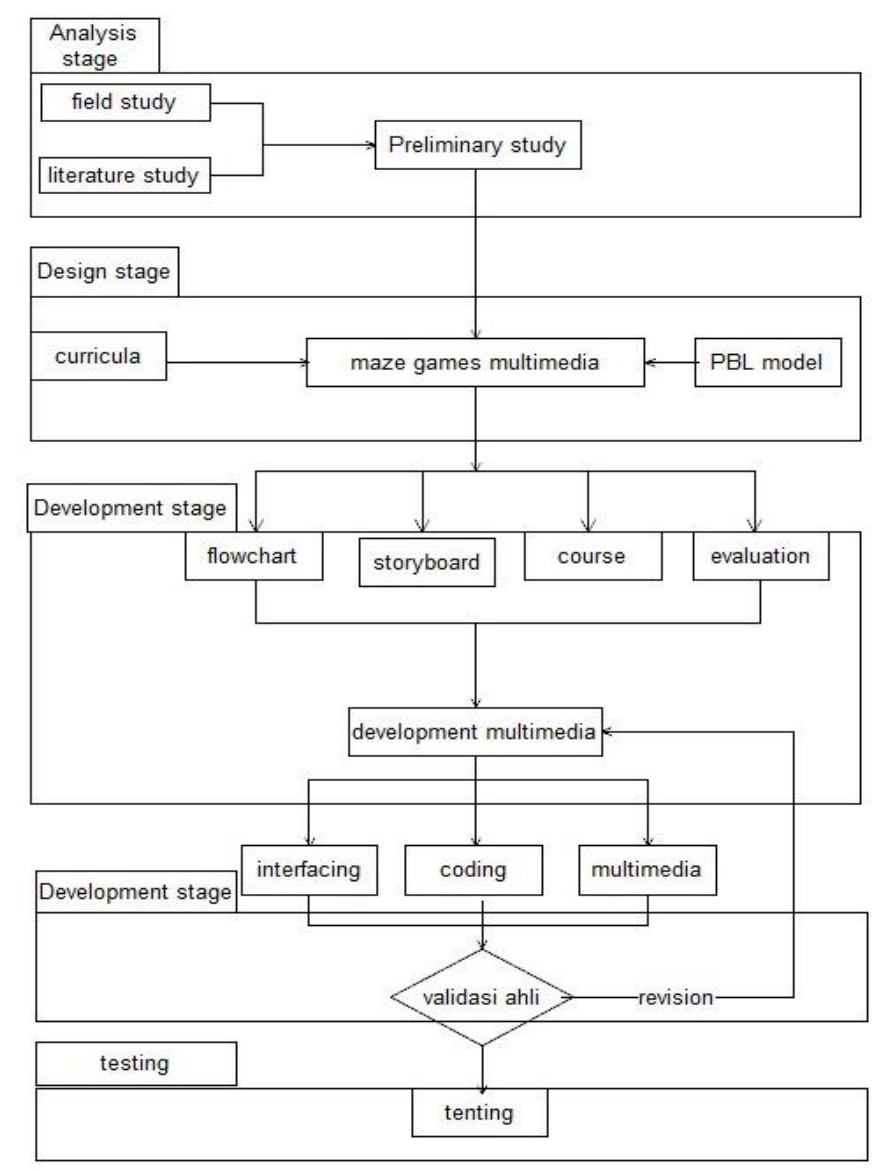

Figure 2. The phase of multimedia development

\section{Result and Discussion}

Multimedia developed is a multimedia game maze with the material presented using the PBL model. In this section there will be a flowchart that contains the sequence of all steps in multimedia developed and shown where PBL steps are implemented in multimedia.

The implementation of PBL in multimedia as shown in flowchart is displayed in Figure 3 , described as follows: PBL begins by presenting the problem to be solved by students, and then the students should be able to analyze the problem given, followed by a report and solution, and ended by conclusions. 


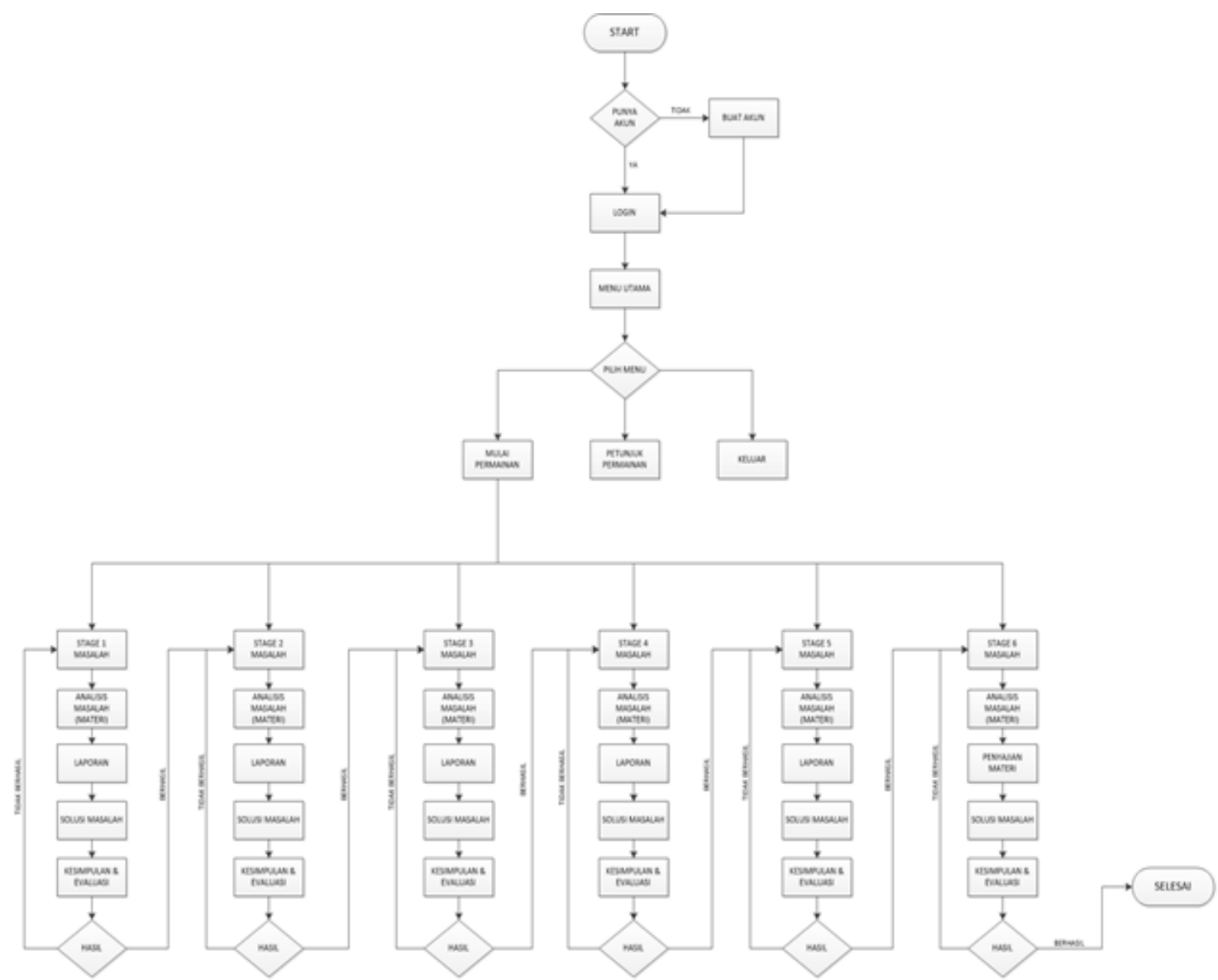

Figure 3. Flowchart of PBL in Multimedia

After the flowchart was developed it was continued with the development of a multimedia display. In this section we will present a multimedia display that implements PBL steps. All steps must be passed from defining, analyzing, problem-solving, and presenting as well as evaluating. In detail, each display of PBL in multimedia is presented as follows:

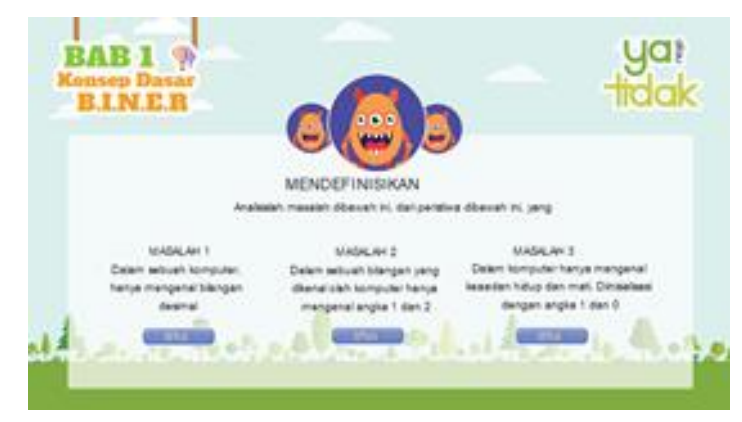

Figure 4. Defining the problem

In Figure 4 shows the step of problem definition in PBL which is interpreted in the multimedia display. Problem definition: The multimedia displays problems that will be encountered by users. Users are required to be able to solve the problems and to properly absorb and analyze it. The problems given are in the form of questions related to the material learned. 


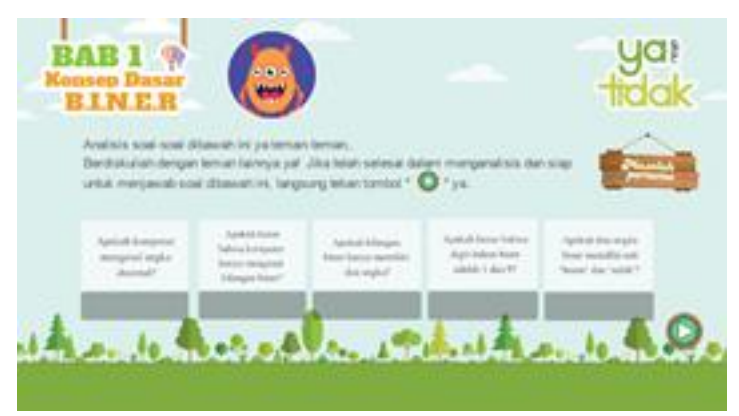

Figure 5. Problem analysis

In Figure 5 shows the step of analyzing the problem in PBL which is interpreted in the multimedia display. Problem analysis: In this phase, users will encounter several problems. The problems given are in the form of questions related to the material learned. Users are required to be able to analyze the problems, either having discussion with friends or being critical.

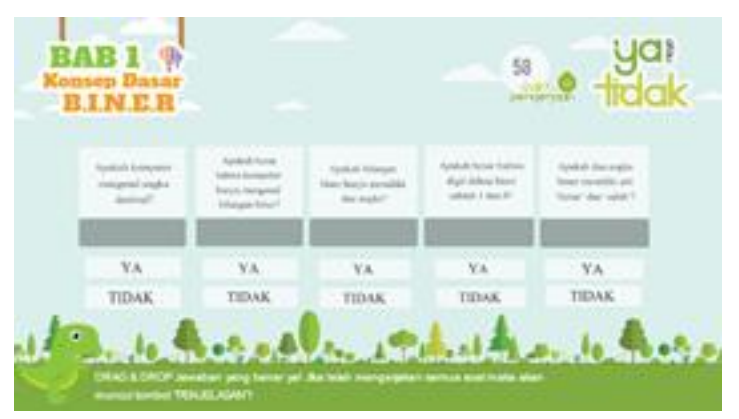

Figure 6. Problem report

In Figure 6 shows the steps to report a problem with PBL which is interpreted in the multimedia display. Report: In this phase, users will encounter the previous problems. Not only analyzed the problem, but also the user is required to be able to report/answer the results of the previous analysis. This phase gives time constraints. If a user exceeds the time limit then he/she is considered failed and has to go back to the early stages of the chapter.

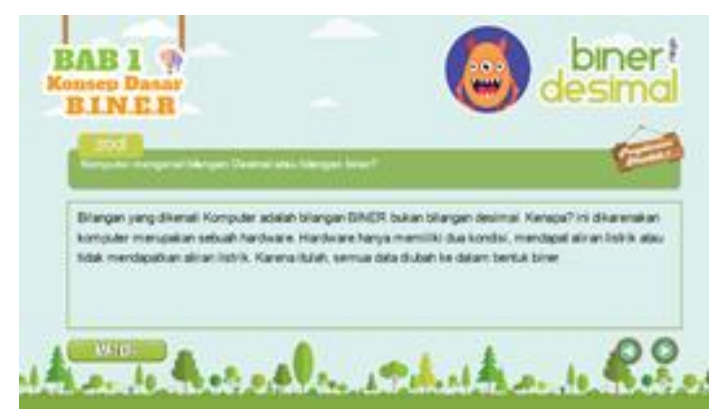

Figure 7. Solution

In Figure 7 shows the solution steps for the problem in PBL which is interpreted in the multimedia display. Solution: This phase presents a solution which is implemented in multimedia by conveying the answers to the problems encountered by students previously. It also aims to let users be able to see whether the understanding they had before is correct or wrong. 


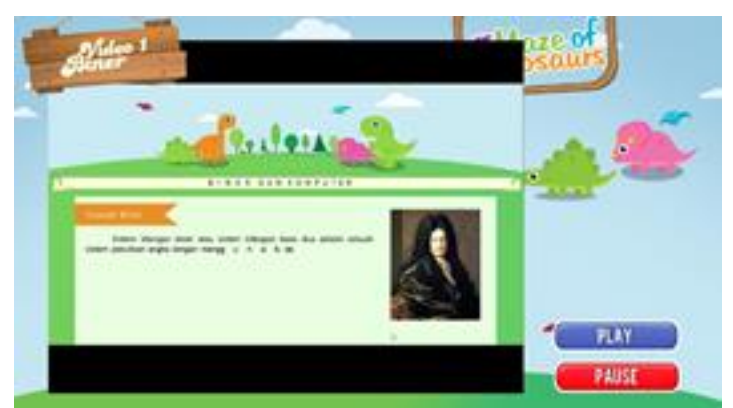

Figure 8. Material

Materials (Figure 8): The material is presented in the form of a coherent delivery of material. The material presents a summary of the problems encountered by previous users. The material is coherent and structured, so that will be easily understood by the user.

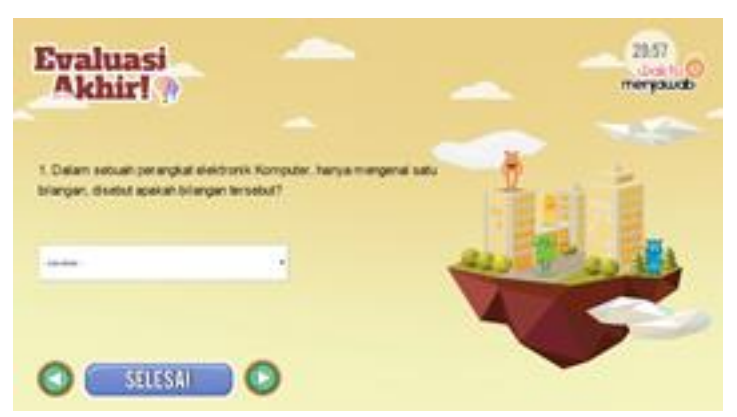

Figure 9. Evaluation

Evaluation (Figure 9): In this phase, the evaluation will be divided into two, evaluation of each chapter and the final evaluation. In the evaluation of each chapter, the user will be given approximately 10 points. Students are required to gain scores over the minimum requirement which is 70 . If the user gets a score below the minimum requirement at the end of the evaluation, he/she is required to return to the initial stages of the chapter. On the contrary, if the user has already achieved a score over the minimum requirement, then he/she is considered to succeed.

A maze game in multimedia is implemented since the game began. The user is encountered with a number of avenues that must be taken. In order to reach the goal, each stage presents barriers that must be opened by taking/finding the key and answering questions. If the question is answered, then the barrier will be automatically opened and the user can proceed to the next stage.

After all the multimedia development process carried out, testing the multimedia will be the next process. The results obtained were as follows: Aspects validated by the expert of media include aspects of presentation, design, ease of interaction, accessibility, re-usable and standard of compliance, as shown in Table 1.

Table 1. Multimedia testing based on the expert of media

\begin{tabular}{lcccc}
\hline \multicolumn{1}{c}{ Aspects } & items & Ideal score & score & $\%$ \\
\hline Quality of content & 4 & 20 & 17 & 85 \\
Learning process & 4 & 20 & 19 & 95 \\
Feedback & 1 & 5 & 4 & 80 \\
Motivation & 1 & 5 & 5 & 100 \\
\hline \multicolumn{1}{c}{ Averages } & & & 90 \\
\hline
\end{tabular}


Based on Table 1, the percentage of media feasibility is $87.32 \%$, which is "very good". Meanwhile, the aspects validated by the expert of subject matter includes the quality of content/material, learning, feedback, adaption, and motivation, as shown in Table 2.

Table 2. Multimedia validation testing based on the expert of material

\begin{tabular}{lcccc}
\hline \multicolumn{1}{c}{ Aspect } & Number of Point & $\begin{array}{c}\text { Ideal } \\
\text { score }\end{array}$ & $\begin{array}{c}\text { Score } \\
\text { Result }\end{array}$ & $\%$ \\
\hline Design Presentation & 2 & 10 & 9 & 90 \\
Ease of Interaction & 3 & 15 & 13 & 86.6 \\
Accessibility & 2 & 10 & 10 & 100 \\
Reusable & 1 & 5 & 4 & 80 \\
Standard of Compliance & 1 & 5 & 4 & 80 \\
\hline Average & & & & 87.3 \\
\hline
\end{tabular}

Table 2 shows that the percentage of media feasibility is $90 \%$, which is categorized as "very good". The multimedia is further tested to students of the vocational school to find out their response toward the multimedia used in learning. Students tried out all the levels given, up to the final evaluation. Here are the results of the students' response. Based on Table 3, the students' response percentage of $80.02 \%$ is acquired and categorized as "very good".

Table 3. Student's response toward multimedia

\begin{tabular}{lc}
\hline \multicolumn{1}{c}{ Indicator } & $\%$ \\
\hline Learning Goal Alignment & 82.08 \\
Feedback and Adaptation & 78.38 \\
Motivation & 80.83 \\
Presentation Design & 78.80 \\
Interaction Capability & 81.13 \\
Accessibility & 78.91 \\
\hline Average & 80.02 \\
\hline
\end{tabular}

\section{Conclusion}

Implementation of problem based learning model in multimedia development based maze game has been conducted and PBL model can be implemented properly. Multimedia is feasible to be used based on the results of testing by the expert of media and material, and student responses were classified as good and very good. Students' response toward the use of multimedia is very good.

\section{References}

Amir, T. M. (2010). Educational Innovation Through Problem Based Learning How Education Empowers Learners in the Age of Knowledge. Jakarta: Kencana Prenada Media Group.

Anneta, L. A. (2008). Video Games in Education: Why They Should Be Used and How They Are Be-ing Used. Theory into Practice, 47, 229-239.

Bakir, N. (2016) Technology and Teacher Education: A Brief Glimpse of Research and Practice that Have Shape the Field. Journal TechTrends, 60, 21-29.

Barrows, H. S. (1996). Problem-based learning in medicine and beyond: A brief overview. In L. Wilkerson \& W. Gijselaers (Eds). Bringing problem based learning to higher education: Theory and Practice (pp.3-11). San Francisco: Jossey-Bass. 
Boud, D. and Feletti, G., (eds) (1997). The challenge of problem based learning (2 ${ }^{\text {nd }}$ edition). London: Kogan Page.

Crawford, C. (2000). The Art of Computer Game Design. Washington: Washington Press University.

Davies, I. K. (2000). Learning Management. Jakarta: CV. Rajawali.

Dondlinger, M. J. (2007). Educational Video Game Desain: A Review of the Literature. Journal of Applied Educational Technology.

Headland, C., Henshall, G., Cenydd, L. A., and Teahan, W. (2014). Randomised Multiconnected Environtment Generator. Bangor University Technical Report CS-TR- 004-2014.

Johnson, D. W. and Johnson, F.P. (2008). Group theory and group skills. Boston: Allyn and Bacon.

Kent, S. L. (2001). The First Quarter: A 25-year History of Video Games. Washington: BWD Press.

Lawrence J., Yannakakis, G., and Togelius, J. (2014). Cellular Automata for Realtime Generation of Infinite Cave Level. ACM.

Moursund, D. (2006). Introduction to Using Games in Education: A Guide for Teachers and Parents. Oregon: University of Oregon.

Munir. (2013). Multimedia Concepts and Applications in Education. Bandung: Alfabeta

Perkins, D. (1992). Smart School: Better Thinking and Learning for Every Child. New York: The Free Press.

Siburian, J. (2010). Science Learning Model. Jambi: Universitas Jambi

Tan, O.S. (2003). Problem based learning innovation: Using problems to power learning in the $21^{\text {th }}$ century. Singapore: Thomson Learning. 